\title{
BIRD SAFETY COATING FOR ARCHITECTURAL AND COMMERCIAL APPLICATIONS
}

\author{
György Vikor \\ Senior Research and Development engineer, Guardian Orosháza Kft. \\ Csorvási út 31, 5900 Orosháza, Hungary, e-mail: vikorgy@gmail.com \\ Bernd Disteldorf \\ Lead R\&D engineer, Science and Technology, Guardian Europe \\ 19, rue du Puits Romain L-8070 Bertrange, Luxembourg, e-mail: $\underline{\text { bdisteldorf@ guardian.com }}$ \\ Francis Wuillaume \\ Lead R\&D engineer; program manager, Science and Technology Center, Guardian Glass \\ 14511 Romine Road, Carleton, Michigan, USA, e-mail: f.wuillaume@guardian.com

\section{Jian-gang Weng} \\ Lead R\&D engineer; program manager, Science and Technology Center, Guardian Glass \\ 14511 Romine Road, Carleton, Michigan, USA, e-mail: jiangang.weng@gmail.com

\section{Adam Burghardt} \\ Lead R\&D engineer; program manager, Science and Technology Center, Guardian Glass \\ 14511 Romine Road, Carleton, Michigan, USA ,e-mail: a.burghardt@guardian.com \\ Alexender Sobolev \\ Lead R\&D engineer; program manager, Science and Technology Center, Guardian Glass \\ 14511 Romine Road, Carleton, Michigan, USA, e-mail: a.sobolev@guardian.com

\section{Suresh Devisetti} \\ Lead R\&D engineer; program manager, Science and Technology Center, Guardian Glass \\ 14511 Romine Road, Carleton, Michigan, USA, e-mail: s.devisetti@guardian.com

\section{Greg Brecht} \\ Lead R\&D engineer; program manager, Science and Technology Center, Guardian Glass \\ 14511 Romine Road, Carleton, Michigan, USA, e-mail: g.brecht@guardian.com
}

\begin{abstract}
Scientific observations conclude that modern buildings can cause a high number of bird deaths due to birds' collision with glass windows and glass walls. There are many efforts to put bird-deterrent patterns on glass in order to avoid bird collision. To make the patterns environment-friendly and meanwhile invisible for human eye, we developed a special Physical Vapour Deposition coated product, a "first surface (PVD) coating". This paper describes a design for bird-deterrent stack from sputter-coating processes, our method to improve the contrast ratio between coated and uncoated area, followed by some discussions on the tunnel-test results.
\end{abstract}

Keywords: bird safety coating, large area PVD coating UV reflection 


\section{Introduction}

Avian mortality due to collision with windows is estimated to be in billions and believed to be the primary cause for population reduction of some bird species [1]. Studies indicate that birds will strike glass when they try to reach sky or habitat seen through glass or mirrored in glass [2].

Many mitigation methods have been proposed to prevent bird-window collision; examples include installing a screen in front of windows and printing frit patterns on glass. While some methods can effectively reduce bird strikes with windows, they are not widely adopted in architectural applications. One of the possible reasons is those bird-deterrent patterns are visible to human vision; they could negatively affect building aesthetics from outside as well as obstruct residents' view from inside.

It is known that, unlike human beings, many birds are tetrachromatic, with dedicated cone cells for perceiving wavelengths in the ultraviolet (UV) of the light spectrum [3]. If one could utilize such UV sensitivity as a deterrent signal to birds, it'd be possible to achieve good balance between bird safety and human friendliness at the same time. The sputter-coated stack described in this paper aims at this goal.

\section{Basic stack design}

The design strategy for the bird-deterrent stack is to have high reflection in the UV wavelength range and at the same time to keep visible reflection close to that of bare glass. In this case, the bird-deterrent patterns can be visible to birds and barely visible to human beings. Such spectral characteristics can be realized by alternating high- and low- index dielectric materials and adjusting their thickness [4]. For example, a 4-layer stack can render spectral curves in Fig. 1, where Ra is the front reflection from the coating side, BRa the backside reflection, and Ta the transmission. One will note that, in the visible wavelength range, the UV reflecting stack and bare glass have about the same optics.

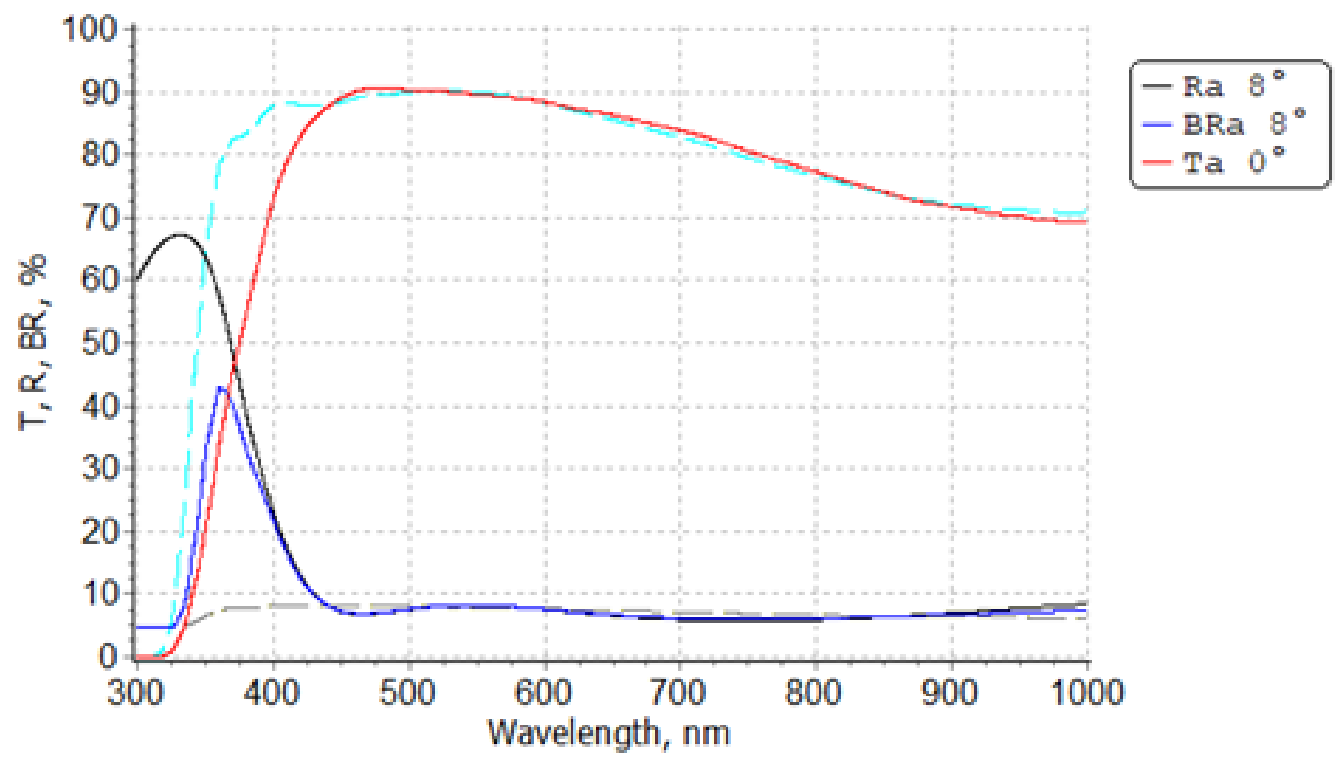

Fig. 1. Spectral curves for a typical UV-reflecting stack. Solid lines are spectral curves of the designed stack; broken lines are spectral curves of bare glass 
In addition, Fig. 1 also indicates that UV reflection at the front side $(\mathrm{Ra})$ is much higher than that in the backside (BRa). The reason is that soda lime glass has absorption at UV wavelengths, which will reduce UV signal greatly when UV light travels through glass twice. In other words, the coating shall be placed at the outer side of a window in order to maximize its effectiveness. As such, a thin layer of chemically durable material would be used to protect the coating from environmental corrosion [4].

\section{IGU implementation}

A typical window has an Insulated Glass Unit (IGU), which consists of two or three panes of glass separated by argon or air. As explained in the previous section, the bird-deterrent coating will be on the outer surface (surface \#1). And some solar-control or (low emissivity) low-e coatings are at an inner surface. A schematic drawing of a double-pane IGU is shown Fig.2 Adding a low-e coating to the inner surface could negatively impact effectiveness of bird-friendly pattern. The reason is that many low-e coatings have some UV reflection even when they are placed at an inner surface. This will reduce contrast ratio of UV reflections between coated area and un-coated area at the front surface. Here the contrast ratio is defined as the ratio of UV reflectance from coated area over that from uncoated area (glass).

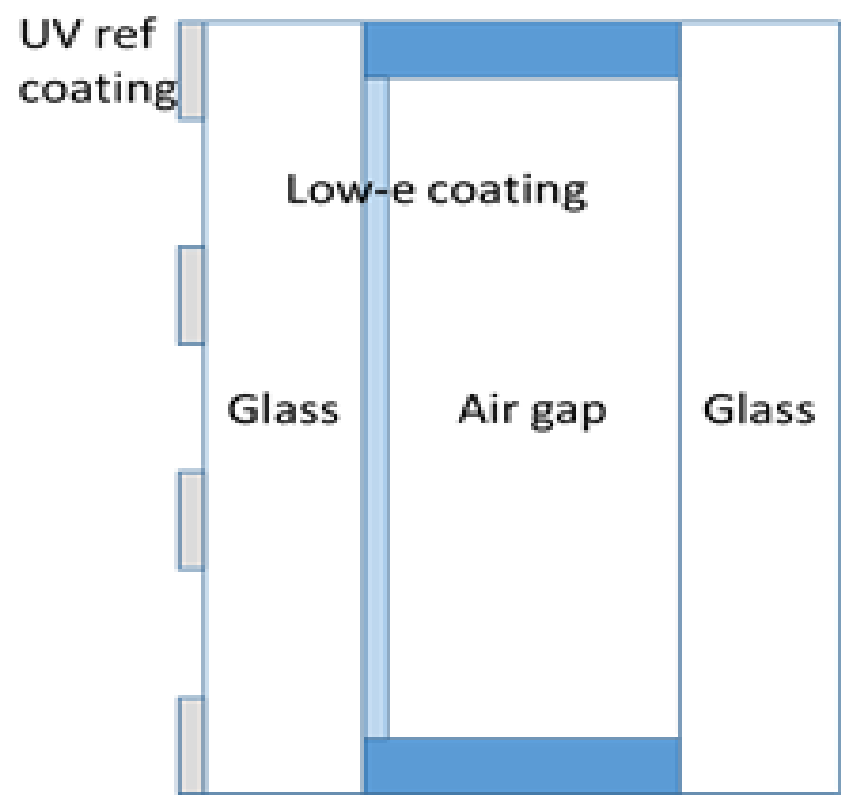

Fig. 2. Typical IGU configuration with bird-deterrent coating on surface \#1 and a low-e coating on surface \#2

Consider an IGU with UV reflective coating at front surface and a typical Guardian double-Ag stack at the inner surface. The plot below illustrates the difference of spectral curves between coated (solid line) and uncoated areas (dotted lines). One will note some increase of UV reflection around 350nm due to the Laminating the front pane with UV-absorbing interlayers, such as PolyVinyl Butyral (PVB), could effectively remove such UV reflection increase [5]. Refer to the schematic in Fig. 4 as the example. Since PVB absorbs UV reflection, there is no UV to reach the low-e coating and to be reflected. As shown in the spectral curves in Fig. 5, there is no more peak around 350nm form the reflection curve of un-coated area; again, solid lines are for coated area and the dotted lines for un-coated area. 


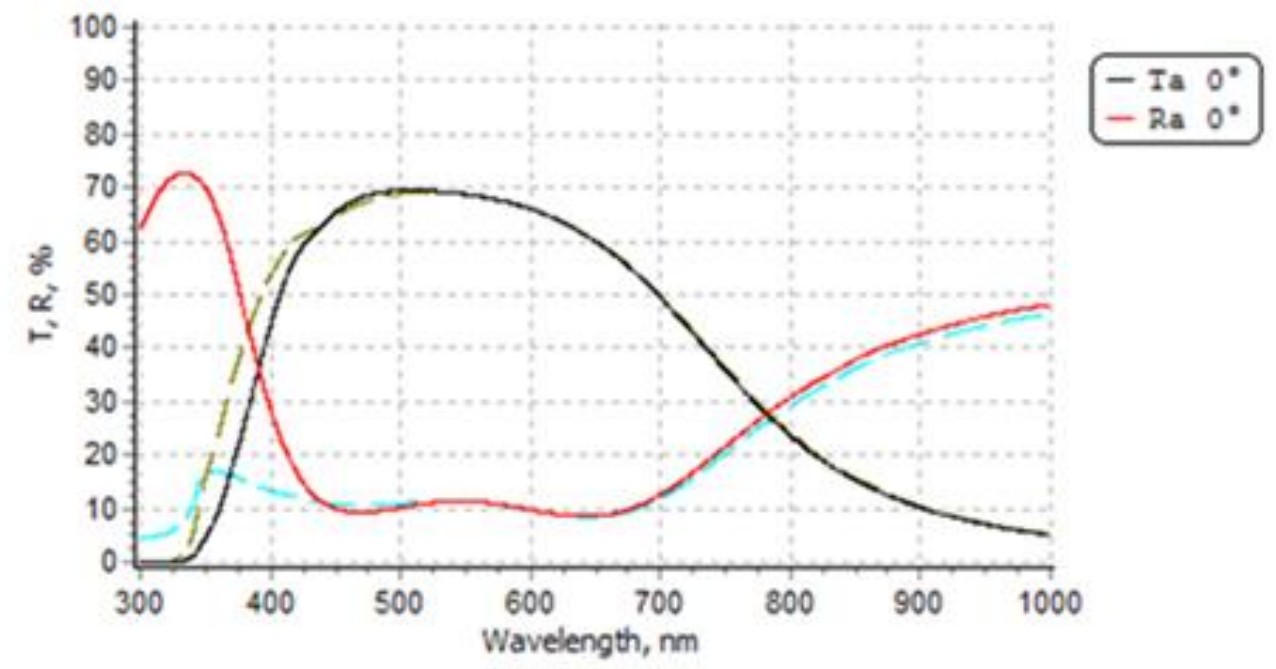

Fig. 3. IGU spectral curves for the IGU configuration in Fig.2. Solid lines are from the coated area and the broken lines are for un-coated area (glass)

\section{Tunnel test results}

The IGU configuration shown in Fig. 4 was sent for tunnel testing conducted by American Bird Conservancy $(\mathrm{ABC})$ in Powdermill, Pennsylvania USA.

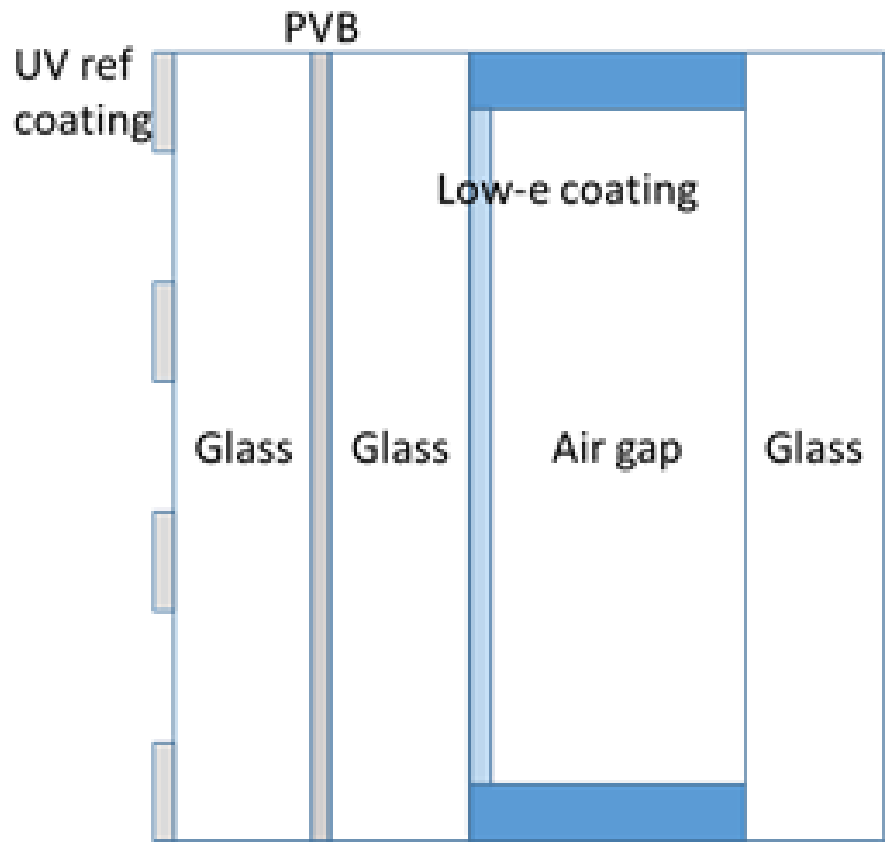

Fig. 4. A typical diagram with front pane lamination. Bird deterrent coating is still on surface \#1 and the low-e coating moves to surface \#4 
The IGU units were tested against a control unit of clear glass. With slightly different pattern designs, the test units consistently received Avoidance Index (AI) score above 70\%. It means that more than 70\% birds flew toward the control unit, indicating that the unit does have the deterrent effect. Useable flights show the number of flights in which birds fly through the tunnel, towards the exit windows.

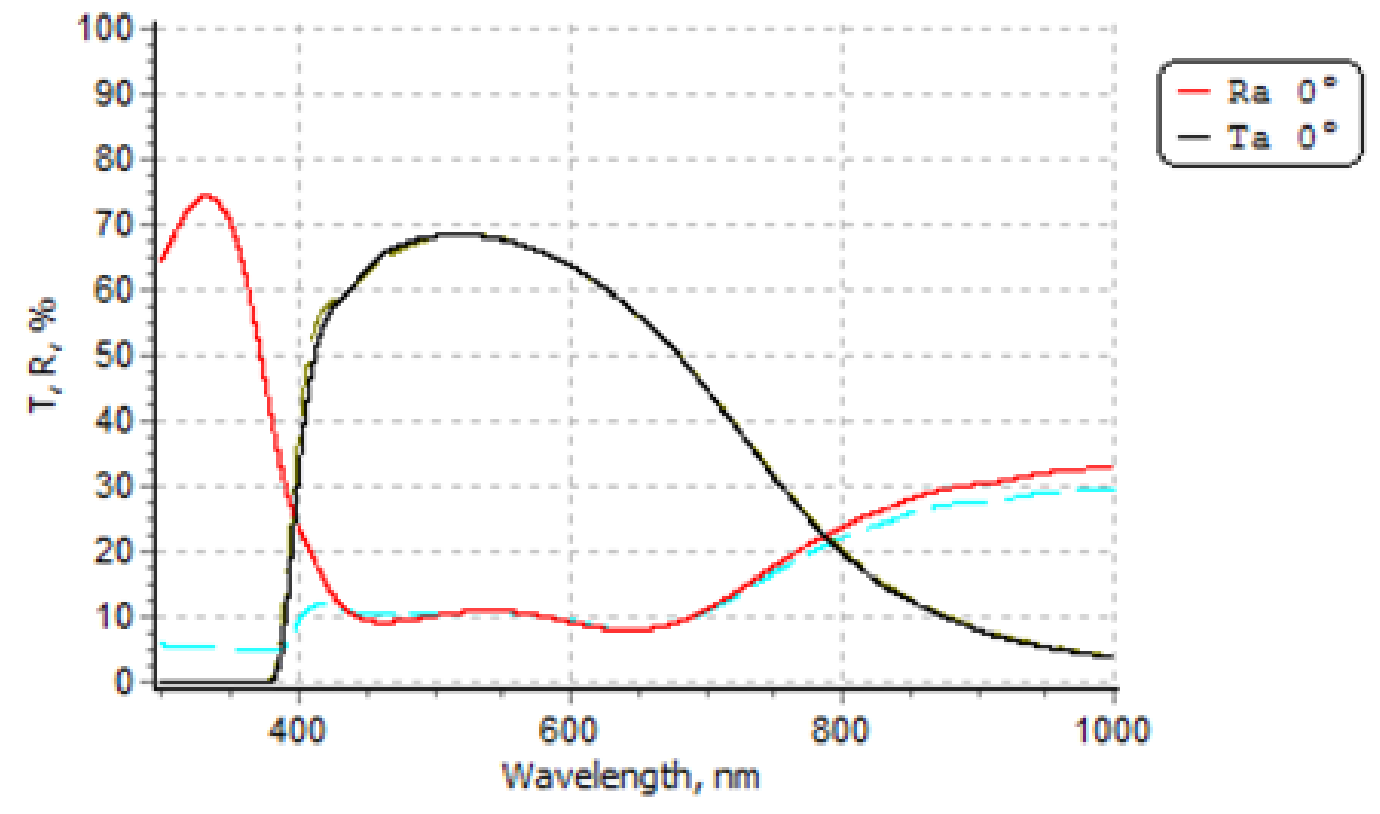

Fig. 5. Spectral curves for the IGU configuration in Fig. 4. Solid lines are for the coated area and the broken lines are for the un-coated area (glass)

Table 1. ABC tunnel test results from 2016 to 2018 on test units with front-pane lamination

\begin{tabular}{|l|c|c|}
\hline & Useable flight & AI score \\
\hline 2016 Fall test & 80 & 74 \\
\hline 2017 Fall test & 80 & 70 \\
\hline 2018 Fall test & 81 & 75 \\
\hline
\end{tabular}

It is worth noting that the test tunnel uses a regular mirror to shine light onto the test unit to make the front-pattern visible to birds; and mirrors always have lower reflectance in UV than in visible wavelength. It is therefore possible that the test score may have underestimated effectiveness of the test units. In real applications where UV light comes directly from ambient environment, the UV-reflecting patterns might be more visible to birds. Details about the final product are advertised on webpage under reference [6]. 


\section{Summary}

Five years of practicing modelling work of thin layers on large area glass surfaces, made us possible to develop an unique magnetron plasma deposition technique to build such a product that is invisible on human eye, but visible to bird eye, due to the UV sensitive bird vision. After six years of investigation and testing time, the product is already in production and shouldt save millions of bird's life each year, depending mostly on rate of use in the architectural applications. The product already won several awards in the North America for environmenatal and architectural applications.

\section{Acknowledgements}

Authors acknowledge guidance and support from colleagues and management at the Science and Technology Center of Guardian Glass.

\section{References}

[1] Klem, D. Bird-Window Collisions: A Critical Animal Welfare and Conservation Issue. Journal of Applied Animal Welfare Science 2015, 18(1):S11-S17. https://doi.org/10.1080/10888705.2015.1075832

[2] Klem, D. Collisions Between Birds and Windows: Mortality and Prevention. Journal of Field Ornithology 1990, 61(1):120-128.

[3] Hart, N. S., Partridge, J. C., Bennett, A. T. D., Cuthill, I. C. Visual pigments, cone oil droplets and ocular media in four species of estrildid finch. Journal of Comparative Physiology 2000, 186:681-694. https://doi.org/10.1007/s003590000121

[4] Vikor, G., Disteldorf, B. US Patent 9650290 (2017)

[5] Weng, J., Wansack, S., Brecht, G., Vandal, R. A.: US Patent application 20190084874 (2018)

[6] https://www.guardianglass.com/us/en/products/brands/guardian-bird1st 